\title{
Architectured helically coiled 3D structures from elastomeric poly(butylene succinate)(PBS) copolyester
}

\author{
Agueda Sonseca ${ }^{1, \dagger}$, Rahul Sahay ${ }^{1}$, Karolina Stepien ${ }^{1}$, Julia Bukala ${ }^{1}$, Aleksandra Wcislek ${ }^{l}$, \\ Andrew McClain ${ }^{2}$, Peter Sobolewski ${ }^{1}$, XiaoMeng Sui ${ }^{3}$, Judit E. Puskas ${ }^{2}$, Joachim Kohn ${ }^{4}$, H. \\ Daniel Wagner ${ }^{3}$, Miroslawa El Fray ${ }^{{ }^{*}}$
}

\author{
${ }^{l}$ Division of Functional Materials and Biomaterials, Polymer Institute, Faculty of Chemical \\ Technology and Engineering, West Pomeranian University of Technology, Szczecin, Al. \\ Piastow 45, 71-310 Szczecin, Poland \\ ${ }^{2}$ Akron Engineering Research Center AERC, The University of Akron, Akron, OH, USA \\ ${ }^{3}$ Department of Materials and Interfaces, Weizmann Institute of Science, Rehovot, 76100, \\ Israel \\ ${ }^{4}$ New Jersey Center for Biomaterials, Rutgers, The State University of New Jersey, \\ Piscataway, NJ, USA \\ *Corresponding author: mirfray@zut.edu.pl \\ ${ }^{\dagger}$ Current address: Instituto de Ciencia y Tecnología de Polímeros, ICTP-CSIC, Calle Juan de \\ la Cierva 3, 28006, Madrid, Spain
}

\begin{abstract}
Electrospinning is one of the most investigated methods used to produce polymeric fiber structures that mimic the morphology of native extracellular matrix. These structures have been extensively studied in the context of scaffolds for tissue regeneration. However, the compactness of materials obtained by traditional electrospinning, collected as two-dimensional non-woven scaffolds, can limit cell infiltration and tissue ingrowth. In addition, for applications in smooth muscle tissue engineering, highly elastic scaffolds capable of withstanding cyclic mechanical strains without suffering significant permanent deformations are preferred. In order to address these challenges, we report the fabrication of microscale 3D helically coiled structures (referred as 3D-HCS) by wet-electrospinning method, a modification of the traditional electrospinning process in which a coagulation bath (non-solvent system for the electrospun material) is used as the collector. The present study, for the first time, successfully demonstrates the feasibility of using this method to produce various architectures of 3D helically coiled structures (HCS) from segmented copolyester of poly(butylene succinate-co-dilinoleic succinate) (PBS-DLS), a thermoplastic elastomer. A mechanism for the HCS formation is proposed and verified with experimental data.

Fabricated 3D-HCS showed high specific surface area, high porosity, and good elasticity. Further, the marked increase in cell proliferation on 3D-HCS confirmed the suitability of these materials as scaffolds for soft tissue engineering.
\end{abstract}

KEYWORDS: electrospinning; polyester; scaffolds; coagulation bath collector; helically coiled architectures 


\section{INTRODUCTION}

Natural materials are characterized by their complex hierarchal structures with a tight coupling between structure and function. These aspects have served as inspiration for materials scientists and engineers in the design of advanced functional materials. ${ }^{1}$ Of particular interest are micro/nanoscale helically coiled structures (HCS), possessing unique morphology and interesting properties (electrical, magnetic, optical, etc.) as well as high stretchability and mechanical stability. ${ }^{2,3}$ The techniques employed to fabricate nanoscale helical structures include sol-gel, selective etching, and self-organization. ${ }^{4-6}$ For example, manganese oxide helical structures have been produced from the contraction of a sol-gel in a capillary tube upon solvent evaporation, ${ }^{5}$ while Kong et al. ${ }^{7}$ obtained zinc oxide nano-helical structures by induced spontaneous polarization.

Varied fiber morphologies, including HCS, can also be obtained by electrospinning. ${ }^{8}$ Different strategies have been reported to achieve the microscale coiled morphology, based either on the combination of two polymers with specific different physical properties, like differential shrinkage or conductivity, ${ }^{9-11}$ or in single polymeric systems, by modifying the concentration of the polymer and/or the solvent system. ${ }^{12,13}$ While various applications of these materials can be envisioned, some of the properties of such coiled electrospun fiber structures, such as high porosity, flexibility and elasticity, are particularly advantageous in the context of tissue engineering scaffolds or templates. Further, the past 20 years have seen a shift to so-called "functional tissue engineering," which emphasizes the critical role of structure and biomechanics in tissue engineering functional tissue constructs. ${ }^{14,15}$ In this context, HCS mimic the architecture and behavior of human soft tissues, such as the heart muscle perimysium composed of microscale coiled fibers. ${ }^{16}$ Additionally, highly elastic scaffolds based on elastic biomaterials have been demonstrated to better maintain their integrity (low permanent deformations) and structure, ${ }^{17,18}$ which is especially useful when working under cyclic loads, such as occurs in cardiac muscle. However, all these traditional electrospinning based methodologies have yielded 2D coiled structures, while functional tissue constructs need to be 3D. Highly porous, 3D structures can be obtained via an alternative electrospinning approach: using a coagulation bath of non-solvent as the collector. ${ }^{19-32}$ While these studies produced 3D structures composed of fibers that are not straight, the random fiber morphology is very far from the desired coiled, hierarchal morphology. However, recent work by Taskin et al. ${ }^{33}$ describes electrospinning of polycaprolactone (PCL) into an ethanol coagulation bath to obtain highly porous 3D structures composed of coiled fibers, which facilitated myofibroblast differentiation and contraction. However, the authors do not describe the role of process parameters on coil morphology nor describe whether different fiber morphologies are achievable. Further, while these results are very promising, PCL is a thermoplastic polyester and lacks the elastomeric properties desirable for truly functional cardiac tissue engineering.

Here we demonstrate the effectiveness of wet-electrospinning for the fabrication of microscale 3D HCS over a range of architectures from a new segmented copolymer, namely poly(butylene succinate-co-dilinoleic succinate)(PBS-DLS). Our goal was to mimic both the $3 \mathrm{D}$ coiled morphology and the elasticity of the perimysium of cardiac tissue. The PBS-DLS 70:30 copolymer chosen for HCS fabrication belongs to the family of polyester thermoplastic elastomers based on succinic acid, 1,4-butanediol, and dilinoleic diol, that we have developed for heart tissue engineering. ${ }^{34}$ PBS-based copolymers containing dilinoleic acid/diol degrade into non-cytotoxic products and their properties can be modulated by varying the ratio of hard 
to soft segments covering a wide range of strength and elasticity. ${ }^{34-38}$ Therefore, PBS-DLS represents a good candidate material to contribute elastic properties to the scaffold, in synergy with the 3D HCS morphology. We investigated the morphology, thermal, and mechanical properties of 3D HCS, as well as their cytocompatibility. Furthermore, we elaborate a critical analysis of the forces acting on the electrospun jet in order to understand the evolution of HCS morphology during wet-electrospinning.

\section{MATERIALS AND METHODS}

Dichloromethane (DCM: $\geq 99.5 \%$ ), succinic acid (SA: $\geq 99 \%$ ) and 1,4-butanediol (BD: 99\%) were purchased from Sigma Aldrich (Poznań, Poland). Dimer linoleic diol (named here as dilinoleic diol), (DLA-OH) Pripol ${ }^{\mathrm{TM}} 2033$ (dimer alcohol $\geq 96.5 \%$ ), was purchased from Croda Coatings \& Polymers, Gouda (The Netherlands). Chloroform $\left(\mathrm{CHCl}_{3}: \geq 98.5 \%\right)$ and methanol (MeOH: $\geq 99.8 \%$ ) were purchased from POCh (Gliwice, Poland) and titanium dioxide based catalyst, $(\mathrm{TiO})_{2}$ (C-94, Huntsman). All the reagents were used as received.

\section{Synthesis of PBS-DLS copolymer}

Poly(butylene succinate-co-dilinoleic succinate) 70:30 wt.\% of hard to soft segments was synthesized as part of a multiblock copolymers series containing dimer linoleic diol. DLA-OH was employed as building block of the dilinoleic-succinate soft segments (DLS) while poly(butylene succinate) (PBS) units constituted the hard segments. Previously reported twostep synthesis procedure for PBS-DLS 50:50 copolymer was employed. ${ }^{35}$ Briefly, esterification stage $\left(1^{\text {st }}\right.$ step) was carried out at $180{ }^{\circ} \mathrm{C}$, until $95 \%$ of theoretical amount of water sub-product was collected, in the presence of succinic acid, 1,4-butanediol and titanium dioxide based catalyst $(\mathrm{TiO})_{2}(\mathrm{C}-94)$. Dilinoleic diol was added to the reaction mixture, temperature was increased to $250{ }^{\circ} \mathrm{C}$ at an approximated rate of $1.5^{\circ} \mathrm{C} / \mathrm{min}$, and pressure was decreased to $0.2-0.4 \mathrm{hPa}$ in order to start the polycondensation stage $\left(2^{\text {nd }}\right.$ step). The reaction was monitored by power consumption of the stirrer and was finished when indicated that the highest melt viscosity was reached. The molar ratio between acid and diols was set at 1:2.2.

\section{Electrospinning process}

The electrospinning setup consisted of high voltage direct current power supply (Gamma HV Research ES30P) attached to the $21 \mathrm{G}$ needle. Polymer solution was fed through the needle via a syringe inserted in a syringe pump (Ascor AP14). The counter-electrode was either a conventional grounded metallic flat collector (length $\sim 15 \mathrm{~cm}$ and width $\sim 15 \mathrm{~cm}$ ) in a horizontal assembly for conventional electrospinning or a non-solvent coagulation bath (see Figure 1) in a vertical assembly for wet electrospinning. The non-solvent bath was a shallow glass container with diameter $\sim 19.5 \mathrm{~cm}$ and height $\sim 2 \mathrm{~cm}$. Electrospinning was performed at $\sim 25{ }^{\circ} \mathrm{C}$ temperature and $\sim 30 \%$ relative humidity. Various parameters of both conventional and bath collector processes were varied in order to assess their effect on the fiber morphology and HCS architecture, including copolymer solution concentration, system parameters (voltage, distance and flow rate), and different non-solvent coagulation baths (deionized water or methanol). After both conventional and wet electrospinning, scaffolds were vacuum dried for $72 \mathrm{~h}$ and morphology was characterized using laser scanning microscopy (LSM, Keyence VK-9700K) and scanning electron microscopy (SEM, Hitachi SU-70). Samples for LSM were visualized without any preparation, while samples for SEM were sputtered with a 60 Å layer of gold using a Leica EM ACE 600 sputter coater. 




Grounded coagulation bath

Figure 1. Schematic of wet-electrospinning setup used for collecting helically coiled structures.

\section{Characterization Methods}

The chemical structure of the obtained copolymer was verified by nuclear magnetic resonance $\left({ }^{1} \mathrm{H}\right.$ NMR, ${ }^{13} \mathrm{C}$ NMR) and infrared spectroscopy (ATR-FTIR). TM Bruker DPX $400(400 \mathrm{MHz})$ spectrometer was used to record ${ }^{1} \mathrm{H}$ NMR (128 scans, 1 second relaxation delay) and ${ }^{13} \mathrm{C}$ NMR (5120 scans, 1 second relaxation delay) spectrum. $\mathrm{CDCl}_{3}$ was employed as a solvent and tetramethylsilane (TMS) as an internal reference. Fourier transform infrared spectra (FTIR) were collected and averaged from 32 scans across the spectral range of 400 to $4000 \mathrm{~cm}^{-1}$, with a $2 \mathrm{~cm}^{-1}$ resolution, using a Bruker ALPHA spectrometer with an Attenuated Total Reflectance (ATR) cell. Samples were vacuum-dried prior to measurement.

The number-average molecular weight $\left(\mathrm{M}_{\mathrm{n}}\right)$, weight-average molecular weight $\left(\mathrm{M}_{\mathrm{w}}\right)$, and polydispersity index (PDI) of the PBS-DLS copolymer were determined by gel permeation chromatography (GPC). The experiment was conducted on a Tosoh EcoSEC, equipped with 2 fused silica separation columns and four detection systems: Dual Absorbance UV (UV, Waters 2487, wavelength $\lambda=254 \mathrm{~nm}$ ), multi-angle laser light scattering (MALLS, Wyatt mini-DAWN Treos), refractive index (RI, Wyatt OPTILAB DSP), and viscometer (VIS, Wyatt ViscoStar-II). Measurements were carried out with $\mathrm{CHCl}_{3}$ (HPLC grade, Alfa Aesar) continuously distilled from $\mathrm{CaH}_{2}$ as the mobile phase at a flow rate of $0.7 \mathrm{~mL} / \mathrm{min}$. Volumes of $15 \mu \mathrm{L}$ were injected at $2-3 \mathrm{mg} / \mathrm{mL}$ sample concentration. Refractive index increment $(\mathrm{d} n / \mathrm{d} c)$ value was calculated from concentration and calculated mass, assuming $100 \%$ mass recovery from the columns. ASTRA 6 software package (Wyatt Technologies) was used to analyze the data and to obtain the number-average molecular weight $\left(\mathrm{M}_{\mathrm{n}}\right)$, weight-average molecular weight $\left(\mathrm{M}_{\mathrm{w}}\right)$, and polydispersity index (PDI) of the PBS-DLS 70:30 copolymer. 
The thermal behaviour of PBS-DLS 70:30 was studied using a TA Instruments DSC Q100 differential scanning calorimeter. Measurements were carried out in a heating-coolingheating cycle over the temperature range from -90 to $200^{\circ} \mathrm{C}$, at a heating/cooling rate of $10{ }^{\circ} \mathrm{C} \mathrm{min}^{-1}$, under a $\mathrm{N}_{2}$ atmosphere. The glass transition temperature $\left(\mathrm{T}_{\mathrm{g}}\right)$ was calculated as the midpoint of the transition in the second heating run.

The mechanical properties of electrospun scaffolds were characterized with static tensile testing, using a universal testing machine (Instron 3366, Instron Co., Ltd., USA) at room temperature. The measurements were carried out at the crosshead speed of $1 \mathrm{~mm} / \mathrm{min}$ from 0 to $0.5 \%$ elongation (to calculate the Young's modulus) and $10 \mathrm{~mm} / \mathrm{min}$ from $0.5 \%$ elongation, using a $500 \mathrm{~N}$ load cell. In order to improve handling of the electrospun materials and avoid preloads on the samples before the mechanical tests, square paper frames were used. The samples were cut into rectangular strips, $5 \mathrm{~mm}$ wide and $4 \mathrm{~cm}$ long, while the internal length of the framework was $2 \mathrm{~cm}$. Sample thickness was measured by using a coating thickness gauge (Elcometer Instruments GmbH, Germany) calibrated with Elcometer thickness standards before the test.

The porosity of samples was measured using liquid displacement method with ethanol as the immersing liquid $\left(\rho=0.80424 \mathrm{~g} / \mathrm{cm}^{3}\right)$ at $19^{\circ} \mathrm{C}$. The, open porosity, $P_{0}$ (Equation 1), was calculated as follows:

$P_{0}=\frac{\left(m_{n}-m_{s}\right)}{\left(m_{n}-m_{w}\right)} \cdot 100 \%$

where, $P_{0}$ is the open porosity, $\mathrm{m}_{\mathrm{s}}$ is the mass of dry sample $[\mathrm{g}], \mathrm{m}_{\mathrm{n}}$ is the mass of sample saturated by immersion liquid [g], $\mathrm{m}_{\mathrm{w}}$ is the mass submerged in the immersion liquid [g]. 3 specimens per sample were tested and averaged.

The 3D architecture, as well as porosity, was also investigated by micro-computed tomography ( $\mu \mathrm{CT}$; Xradia XCT-400, ZEISS, Germany) at $40 \mathrm{kV}$, current of $250 \mathrm{uA}$, and exposure time of 15 seconds. Scaffold porosity was determined using Analyzer software (Bruker).

\section{In vitro cell culture}

Cytotoxity of electrospun scaffolds was tested via extract test and direct contact test, based on ISO10993-5, ${ }^{39}$ using L929 murine fibroblasts. Briefly, sub-confluent (70-80\%) T25 flasks were trypsinized, cells were counted, and 10,000 cells were plated per well of a 96 well plate in $100 \mu \mathrm{L}$ of complete media (DMEM containing 10\% fetal bovine serum (FBS), $2 \mathrm{mM}$ L-glutamine, $100 \mathrm{U} / \mathrm{mL}$ penicillin, and $100 \mu \mathrm{g} / \mathrm{mL}$ streptomycin). After 24 hours of culture, cells were either exposed to extracts or samples of electrospun fiber materials.

For extracts, conventionally electrospun PBS-DLS scaffolds (50-100 $\mu \mathrm{m}$ thick) were cut into $0.5 \mathrm{~cm}^{2}$ strips and disinfected by soaking in 70\% isopropyl alcohol for 20 minutes. Samples were then triple rinsed in sterile PBS, placed into tubes containing $0.5 \mathrm{~mL}$ of complete cell culture media, and incubated at $37^{\circ} \mathrm{C}$ for 24 hours (a tube containing just media was used as a vehicle control). After incubation, media was collected and (neat or diluted 1:3 with fresh media) used to replace the media of L929 cells seeded 24 hours in advance. After further 24 hours of culture, viability of cells was assessed using resazurin assay. ${ }^{40}$ Briefly, $0.15 \mathrm{mg} / \mathrm{mL}$ sterile resazurin stock in PBS was diluted 1:6 with complete media and $100 \mu \mathrm{L}$ 
was added to each test well after aspirating media. Plate was then incubated for 4 hours at $37^{\circ} \mathrm{C}$ and fluorescence (Em: 540, Ex: 590) was measured using BioTek Synergy HTX multifunctional plate reader.

For direct contact tests, $4 \mathrm{~mm}$ diameter discs of conventionally electrospun PBS-DLS scaffolds were cut using pneumatic punch, disinfected by soaking in 70\% isopropyl alcohol for 20 minutes, and triple rinsed in sterile PBS. Samples were then placed on top of L929 cells seeded 24 hours in advance (following aspiration of media), held in place using Scaffdex CellCrown 96 insert, and covered with $140 \mu \mathrm{L}$ of complete media. As a control, inserts were placed into wells without samples. After 48 hours of culture, inserts and materials were removed and cell viability was assessed using resazurin assay as described above.

In order to compare cell response to conventionally electrospun 2D materials and HCS, $4 \mathrm{~mm}$ diameter samples of conventionally electrospun scaffolds and HCS were cut using pneumatic punch, disinfected by soaking in 70\% isopropyl alcohol for 20 minutes, triple rinsed in sterile PBS, and rinsed in complete media. Each sample was then loaded into a Scaffdex CellCrown 96 insert and the inserts were placed into 96 well-plate wells containing $75 \mu \mathrm{L}$ of complete media. Next, 20,000 L929 cells in $25 \mu \mathrm{L}$ of complete media were carefully pipetted on top of each sample, within the Scaffdex CellCrown 96 insert. After 18 hours of culture to allow for adhesion of cells, inserts were transferred to empty wells and the resazurin assay was used to assess viability as described above. Cells were then maintained in culture on scaffolds and viability was assessed again after additional period of 48 hours (66 total) and then an additional period of 96 hours (162 hours total). Data was analysed using R software. Comparisons were tested by first F-testing for equality of variances, followed by two-sample t-test.

\section{RESULTS AND DISCUSSION Fabrication of $3 \mathrm{D} H C S$}

PBS-DLS copolymer containing 70:30 wt $\%$ of hard to soft segments ratio (Scheme 1) was synthesized by melt polycondensation and its chemical structure was analysed by ${ }^{1} \mathrm{H}$ NMR (Supporting information, Figure S1 and Tables S1 and S2, respectively).

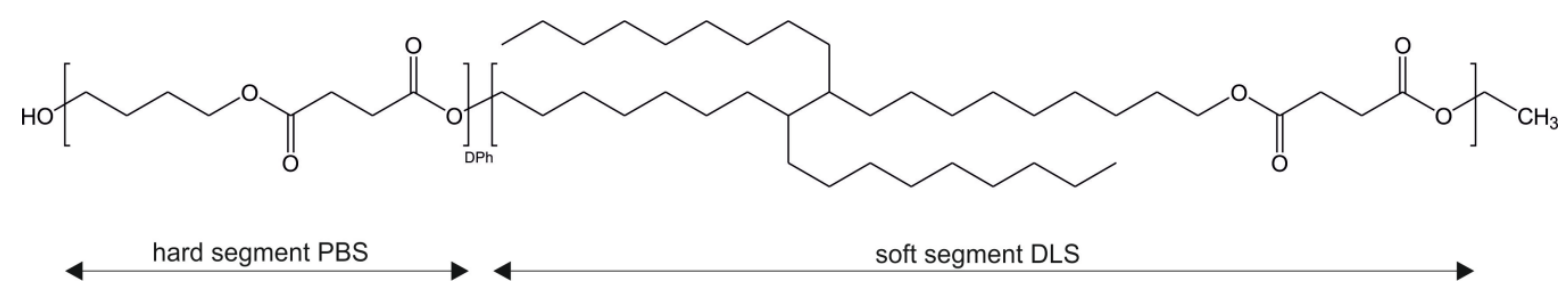

Scheme 1. Chemical structure of poly(butylene succinate-co-dilinoleic succinate) PBS:DLS 70:30 copolymer. DPh - degree of polycondensation of hard segments, 8.49.

${ }^{1} \mathrm{H}-\mathrm{NMR}\left(400 \mathrm{MHz}, \mathrm{CDCl}_{3}, \delta\right): 4.12(4 \mathrm{H}, \mathrm{BD})$ and $1.72(4 \mathrm{H}, \mathrm{BD})$ side $\mathrm{CH}_{2} \mathrm{O}$ and central $\mathrm{CH}_{2}$ of butylene moieties respectively; 2.63 (4H, DS) $\mathrm{COCH}_{2}$ from succinate moieties; 4.16 (2H, DLA-OH), $1.62(20 \mathrm{H}, \mathrm{DLA}-\mathrm{OH}), 1.25(52 \mathrm{H}, \mathrm{DLA}-\mathrm{OH})$ and $0.85(10 \mathrm{H}$, DLA-OH) $\mathrm{CH}, \mathrm{CH}_{2}$ and $\mathrm{CH}_{3}$ from DLA-OH moieties. Low intensity resonances: $3.68(2 \mathrm{H})$ from $\mathrm{CH}_{2}$ attached to $\mathrm{OH}$ end groups. In addition, the hard to soft segments weight $\%$ ratio based on ${ }^{1} \mathrm{H}$ NMR was calculated to be 67:33 (Supporting Information equations S1-S4). FTIR spectrum of PBS-DLS copolymer revealed bands characteristic of polyester-detailed 
assignments are given in Supporting Information (Figure S2). Table 1 summarizes PBS-DLS chemical and physical properties from SEC and DSC analysis.

Table 1. Molecular weight, thermal properties and crystallinity of PBS-DLS synthesized copolymer.

\begin{tabular}{|c|c|c|c|c|c|c|c|c|c|c|}
\hline & $\begin{array}{l}M_{n} \\
\left(10^{3} \mathrm{~g} / \mathrm{mol}\right)\end{array}$ & $\begin{array}{l}M_{w} \\
\left(10^{3} \mathrm{~g} / \mathrm{mol}\right)\end{array}$ & PDI & $\begin{array}{l}\mathbf{T}_{\mathbf{c}} \\
\left({ }^{\circ} \mathrm{C}\right)\end{array}$ & $\begin{array}{l}\mathbf{T}_{\mathrm{g}} \\
\left({ }^{\circ} \mathrm{C}\right)\end{array}$ & $\begin{array}{l}\mathbf{T}_{\mathbf{m}} \\
\left({ }^{\circ} \mathbf{C}\right)\end{array}$ & $\begin{array}{l}\Delta \mathbf{H}_{\mathbf{c}} \\
(\mathbf{J} / \mathbf{g})\end{array}$ & $\begin{array}{l}\Delta \mathbf{H}_{\mathrm{m}} \\
(\mathrm{J} / \mathrm{g})\end{array}$ & $\begin{array}{l}\Delta \mathbf{H}_{\mathrm{m}}^{\mathbf{0}} \\
(\mathrm{J} / \mathrm{g})\end{array}$ & $\begin{array}{l}X_{c} \\
(\%)\end{array}$ \\
\hline $\begin{array}{l}\text { PBS:DLS } \\
70: 30\end{array}$ & 23.7 & 62.3 & 2.6 & 48 & -44 & 98 & 53.2 & 44.0 & 110.3 & 28.0 \\
\hline
\end{tabular}

$M_{w}$ - weight average molar mass, $M_{n}$ - number average molar mass and PDI-polydispersity index form SEC. $T_{c}$-crystallization temperature, $T_{g}$ - glass transition temperature, $T_{m}-$ melting point, $\Delta H_{c}-$ crystallization enthalpy, $\Delta H_{m}-$ melting enthalpy, $\Delta_{m}^{0}-$ melting enthalpy of $100 \%$ crystalline PBS $(110.3 \mathrm{~J} / \mathrm{g})$ and $X_{c}-$ degree of crystallinity of hard segments from DSC. *The glass transition temperature $\left(T_{g}\right)$ was calculated as the midpoint of the transition in the second heating run. The crystallinity content $\left(X_{c}\right)$ was calculated as crystallization degree of hard phase evaluated according to the following equation: $X_{c} \%=\left(0.7 x \Delta H_{m} /\right.$ $\left.\Delta H_{m}^{0}\right) x 100$.

In order to achieve uniform, dense 3D HCS, the parameters of the wet-electrospinning process were varied. First, the role of the non-solvent present in the coagulation bath was tested, comparing deionized water, ethanol, and methanol. When water was used, random electrospun fibers were collected, floating on the surface of the water, as shown in Figure 2a. This is attributed to hydrophobic nature of PBS-DLS fibers and high surface tension of water $(\gamma=72.86 \mathrm{mN} / \mathrm{m})$, resulting in a nonwoven 2D fibrous network. On the other hand, uniform 3D HCS were collected when methanol was used for the coagulation bath (see Figure $2 \mathbf{b}$ ).
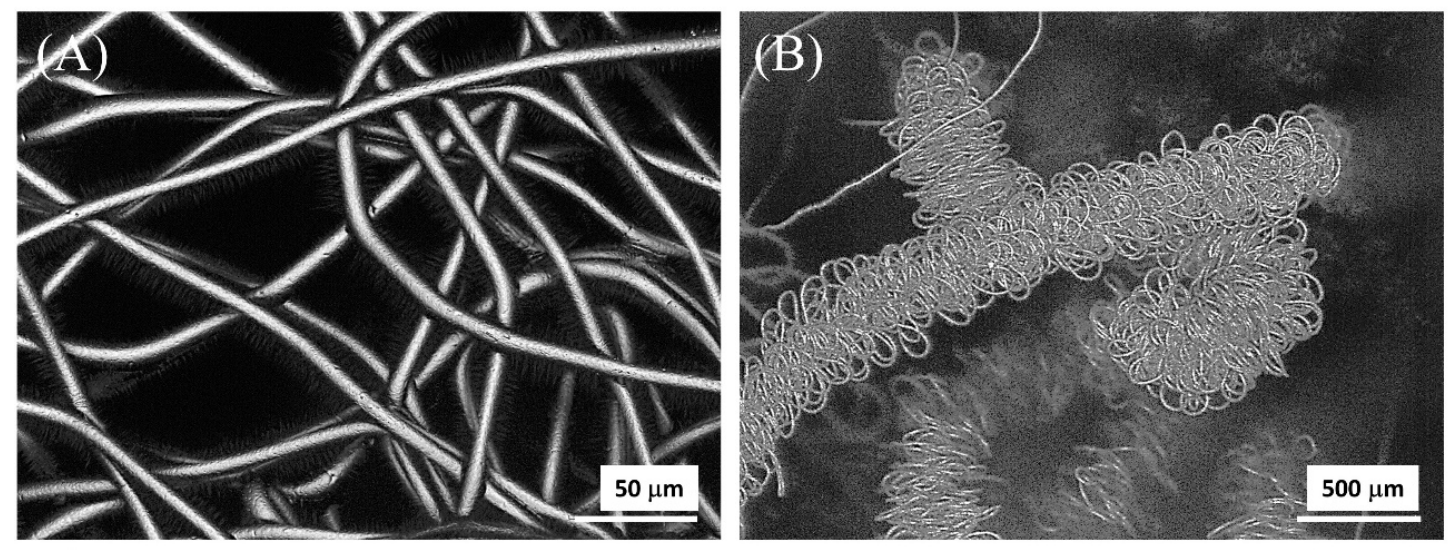

Figure 2. $\mathrm{LSM}$ images of $30 \mathrm{w} / \mathrm{v} \% \mathrm{PBS}$ :DLS 70:30/ $\mathrm{CHCl}_{3}$ collected on (a) water bath as $2 \mathrm{D}$ electrospun scaffold at flow rate $\sim 10 \mathrm{ml} / \mathrm{h}$ and electric field $\sim 0.7 \mathrm{KV} / \mathrm{cm}(17 \mathrm{kV}, 25 \mathrm{~cm}),(\mathrm{b})$ methanol bath as 3D electrospun $\mathrm{HCS}$ at flow rate $\sim 10 \mathrm{ml} / \mathrm{h}$ and electric field $\sim 0.58 \mathrm{KV} / \mathrm{cm}$ $(15 \mathrm{kV}, 25 \mathrm{~cm})$.

In this case, electrospun fibers also initially collect on the surface of the non-solvent bath, but then they sink, creating 3D HCS in the bulk of the liquid bath ${ }^{19,20,27,32}$. In addition to methanol, we also tested ethanol as non-solvent. No major differences were observed in the 
morphology of the HCS obtained in either alcohol bath, likely due similar surface tensions of methanol $(\gamma=22.50 \mathrm{mN} / \mathrm{m})$ and ethanol $(\gamma=22.10 \mathrm{mN} / \mathrm{m})$. As a result, for the remainder of the experiments presented, only HCS collected in methanol bath are discussed. Figure 3 shows macroscopic and LSM images of PBS-DLS 70:30 electrospun scaffolds obtained by conventional electrospinning with a flat metal collector (Figure 3a) and wet electrospinning system filled with $\mathrm{MeOH}$ as a non-solvent in the coagulation bath (Figure 3b). As expected, conventional electrospinning yields dense 2D non-woven scaffolds of PBS-DLS. However, using the non-solvent methanol bath as the collector favors the formation of 3D fibrous HCS.
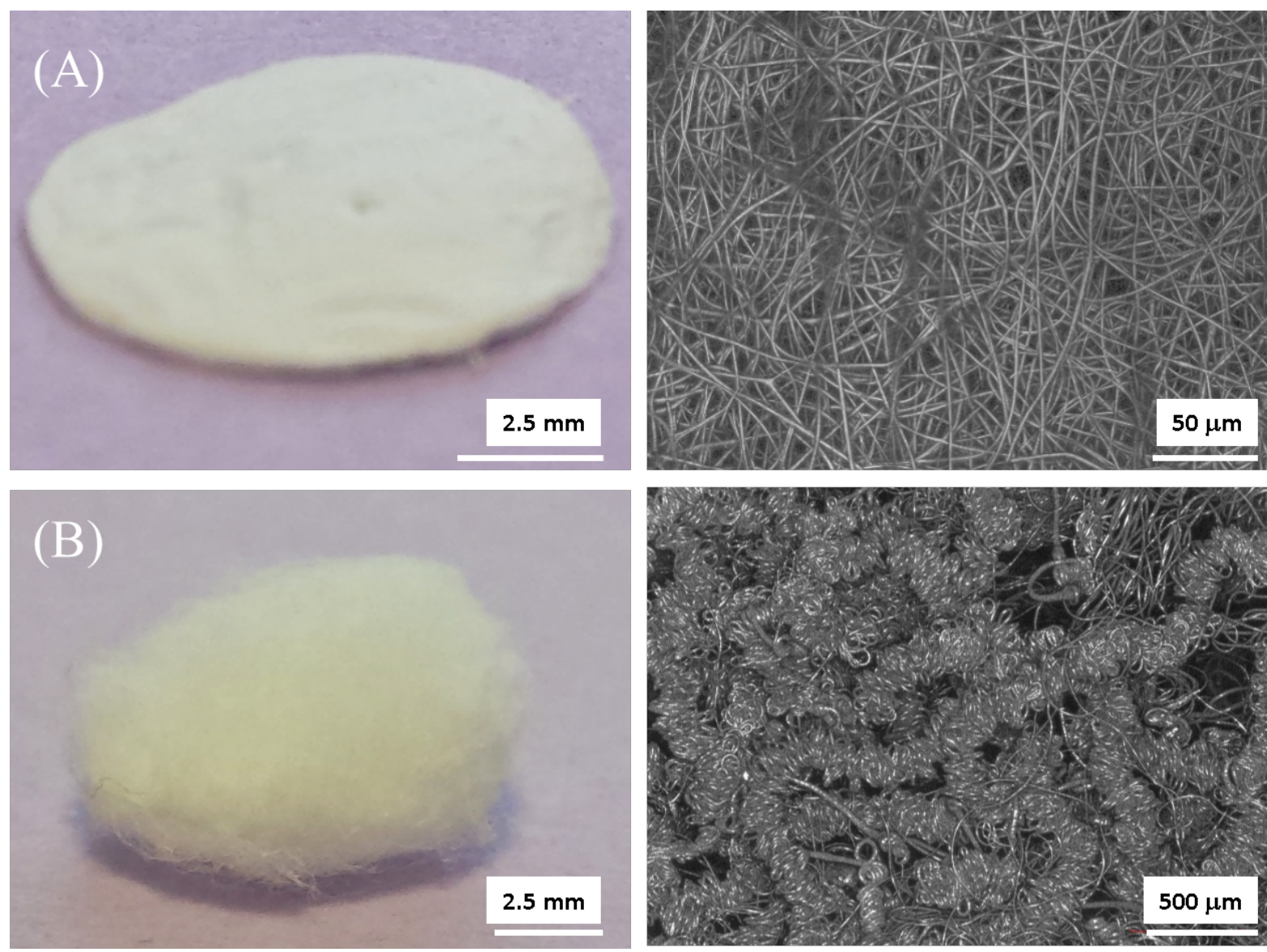

Figure 3. Photos (left) and LSM images (right) of electrospun scaffolds collected on (a) conventional flat collector covered with aluminum foil for $16 \mathrm{wt} / \mathrm{v} \%$ PBS:DLS 70:30 in $\mathrm{CHCl}_{3}: \mathrm{MeOH}(7: 3)$ as a solvent electrospun at electric field $\sim 1 \mathrm{kV} / \mathrm{cm}(17 \mathrm{kV}, 16 \mathrm{~cm})$, and flow rate $\sim 6 \mathrm{ml} / \mathrm{hr}$ as $2 \mathrm{D}$ membrane, and (b) methanol bath for $20 \mathrm{wt} / \mathrm{v} \%$ PBS:DLS 70:30 in $\mathrm{CHCl}_{3}$ electrospun at electric field $\sim 0.65 \mathrm{kV} / \mathrm{cm}(15 \mathrm{kV}, 23 \mathrm{~cm})$, and flow rate $\sim 7 \mathrm{ml} / \mathrm{hr}$ as $3 \mathrm{D}$ membrane consisting of HCS.

Thanks to the low surface tension of $\mathrm{MeOH}(\gamma=22.50 \mathrm{mN} / \mathrm{m})$, during wet electrospinning the fibers sink into the coagulation bath and the liquid prevents subsequent fibers from piling up, favouring a loosely packed structure. The morphology of our PBS-DLS HCS is similar to that of 3D scaffolds obtained from PCL by Taskin et al., ${ }^{33}$ however we observe that the individual coils are more dense and spring-like (Figure $3 b$ ). 
Next, we examined the effect of the remaining parameters, concentration of polymer solution, applied electric field (voltage, distance), and flow rate of the polymer solution, on coil morphology. The concentration of the PBS-DLS 70:30 in chloroform was varied from 15 to $30 \mathrm{wt} / \mathrm{v} \%$, spanning a viscosity range of $123-1035 \mathrm{cPa}$. For a given applied electric field and flow rate, concentrations below $20 \mathrm{wt} / \mathrm{v} \%$ (viscosity $<300 \mathrm{cPa}$ ) resulted in bead-on-string structures, whereas above and including $20 \mathrm{wt} / \mathrm{v} \%$ resulted in uniform HCS; however, $30 \mathrm{wt} / \mathrm{v} \%$ solutions were very viscous $(>1000 \mathrm{cPa})$ and thus difficult to work with. Importantly, for fixed $25 \mathrm{wt} / \mathrm{v} \%$ polymer solution, it was possible to obtain varied HCS morphologies, ranging from a flatter, more ribbon-like architecture, to figure- 8 coils similar to those obtained by Taskin, ${ }^{33}$ and finally to more spring-like coils. The effect of polymer solution flow rate at fixed $9 \mathrm{kV}$ and $15 \mathrm{~cm}$ distance on coil and fiber diameter is shown in Figure 4. We observe that the coil diameter is reduced from over $600 \mu \mathrm{m}$ down to $200 \mu \mathrm{m}$ with the architecture changing from flat, ribbon-like structures to a more coiled morphology with increasing flow rate of polymer solution. Meanwhile, the fiber diameter increases (up to $>18 \mu \mathrm{m}$ ) with increasing flow rate, as is typical for conventional electrospinning.

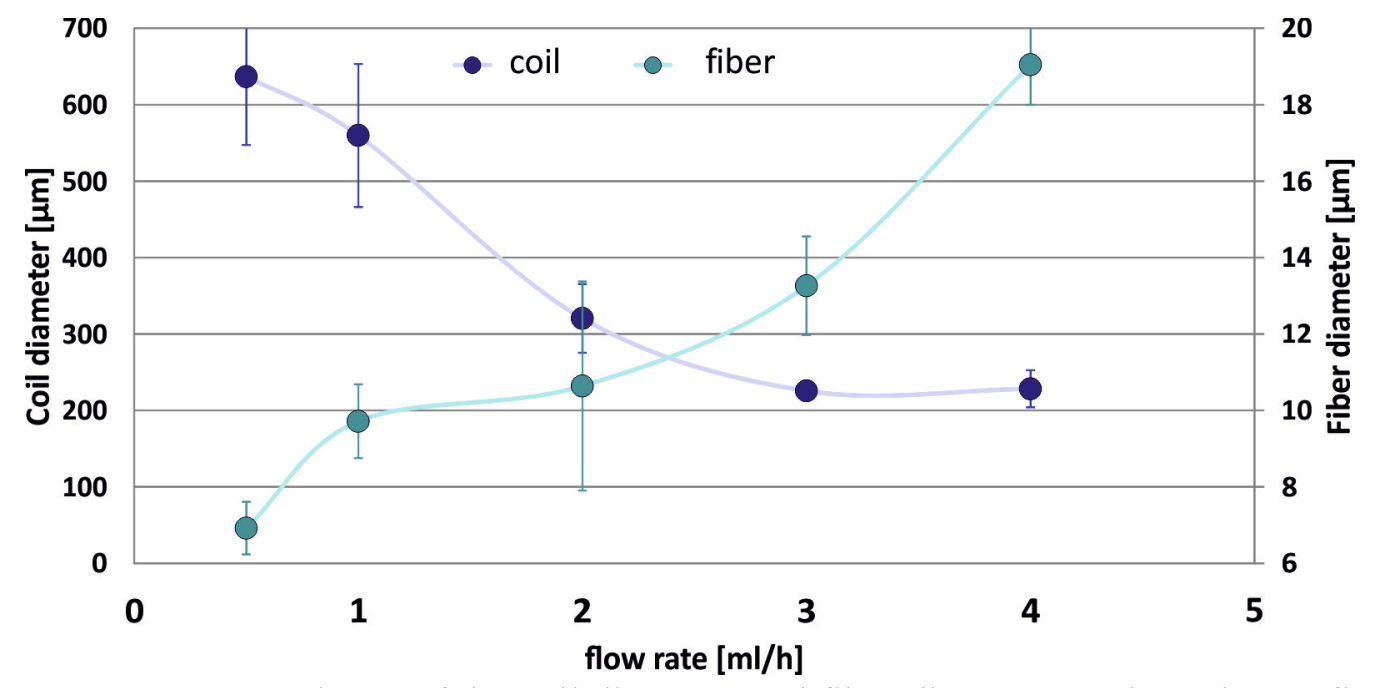

Figure 4. Dependence of the coil diameter and fiber diameter on the polymer flow rate for structures prepared from $25 \% \mathrm{wt} / \mathrm{v}$ polymer solution at distance of $15 \mathrm{~cm}$ and voltage of $9 \mathrm{kV}$.

Next, we fixed the flow rate at $2 \mathrm{ml} / \mathrm{h}$ and examined the effect of the applied voltage at a fixed distance $(15 \mathrm{~cm})$. Again, we observe a marked effect on the size of the coils, as can be seen in Figure 5, with the coil diameter decreasing with increasing voltage applied to the wet collector. However, increasing the voltage did no have a corresponding effect on fiber diameter. 


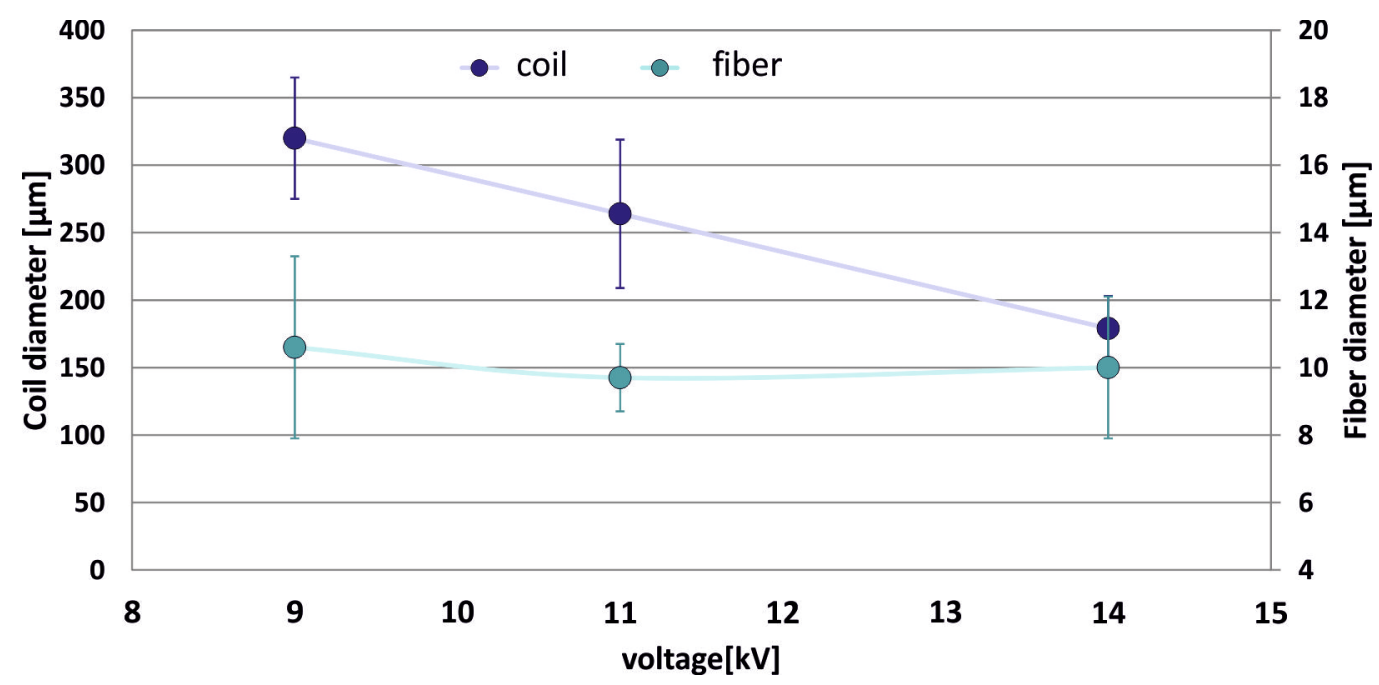

Figure 5. Dependence of the coil diameter and fiber diameter on the applied voltage for structures prepared from $25 \% \mathrm{w} / \mathrm{v}$ polymer solution at distance of $15 \mathrm{~cm}$ and flow rate of 2 $\mathrm{ml} / \mathrm{h}$.

While we used chloroform as the polymer solvent for our work, we were also able to obtain 3D structures using different polymer-solvent systems, such as $20 \mathrm{wt} / \mathrm{v} \% \mathrm{PBS}-\mathrm{DLS}$ (70:30)/dichloromethane solution (Figure 6).

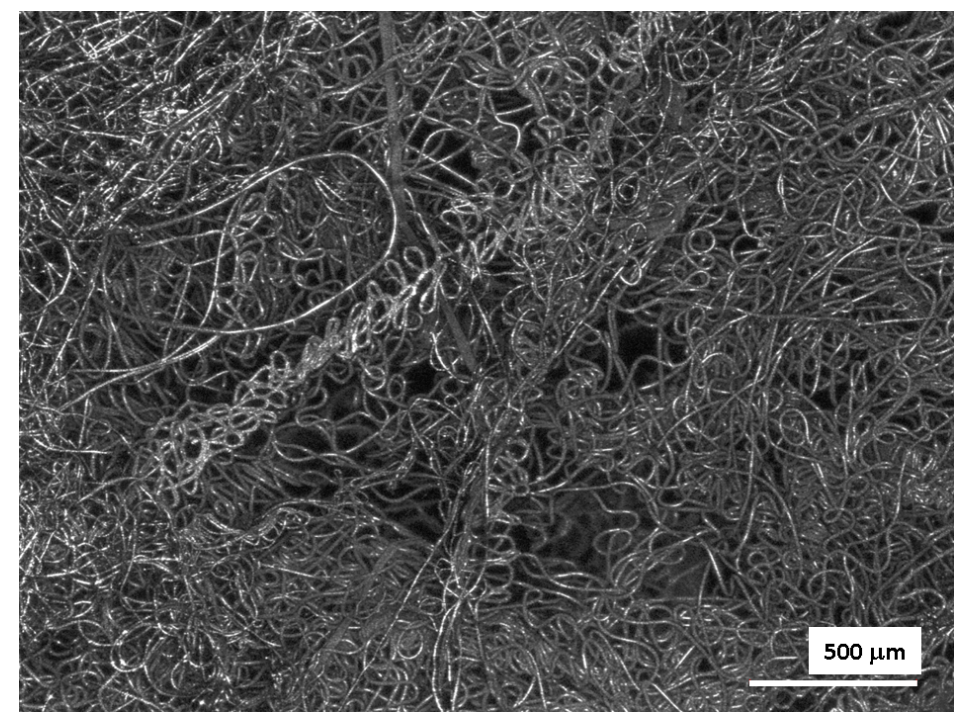

Figure 6. LSM images of 3D electrospun scaffold from $20 \mathrm{wt} / \mathrm{v} \%$ PBS:DLS 70:30/ dichloromethane solution collected in a methanol bath electrospun at electric field $\sim 0.54$ $\mathrm{kV} / \mathrm{cm}(14 \mathrm{kV}, 26 \mathrm{~cm})$, and flow rate $\sim 10 \mathrm{ml} / \mathrm{hr}$.

The fact that by changing process parameters we were able to obtain a broad range of non-random, 3D fiber architectures, ranging from flatter, more ribbon-like to more spring-like demonstrates the thus far underappreciated potential of the wet electrospinning process to be adapted to various tissue engineering applications or other applications requiring 3D fibrous structures. In order to understand the process of coil formation and resulting HCS morphology, we examined the governing mechanics. Over the years, researchers have proposed various mechanisms for the production of HCS. Conventionally, HCS are formed by twisting the fiber 
under the action of tensile force. Ross et al. ${ }^{41,42}$ defined the critical torque $\left(\tau_{c}\right)$ that initiates coiling in anisotropic fibers under a tensile force $\left(F_{t}\right)$ as:

$\tau_{c}=\sqrt{2 F_{t} E I}$

where, $E$ is the fiber's Young's modulus and $I$ is its second moment of area $\left(\pi d^{4} / 64\right)$, considering that the fiber has a circular cross-section with diameter $d$. Similarly, the expression of critical torque for electrospun jet can be rewritten as follows:

$\tau_{c}=\sqrt{\left(F_{t}-F_{v}\right) \frac{E \pi d^{4}}{32}}$

where the tensile component of force due to the electric field acting on the jet can be defined as $F_{t} \approx \sigma A_{t} E_{e}, \sigma$ being the surface charge density of electrospun jet, $A_{t}$ the cross-sectional area of the jet and $E_{\mathrm{e}}$ the applied electric field. ${ }^{43} F_{v}$ is the viscoelastic restoring force, inhibiting stretching of the jet during electrospinning.

As already stated, a torque is required to coil the fiber under the action of tensile force. In case of electrospinning, the normal component of force due to electric field will provide the necessary torque to coil the fibers, given by equation (4): ${ }^{43,44}$

$F_{n} \approx \frac{(\bar{\varepsilon}-\varepsilon)}{2} A_{n} E_{e}^{2}$

where, $\bar{\varepsilon}$ and $\varepsilon$ are the dielectric constant of the surrounding fluid and jet, respectively, and $A_{n}$ is the surface area of the jet. ${ }^{43}$ The coiling/twisting behaviour of the electrospun jet results in its typical 3D non-uniform helical motion. The viscoelastic force $\left(F_{v}\right)$ acts as the restoring force, resisting the stretching and bending of the electrospun jet i.e. it acts against both $F_{t}$ and $F_{n}$. Meanwhile, a reduction in $F_{t}$ or an increase in $F_{v}$ will reduce the torque required to initiate coiling (see Eq. 3,4).

Importantly, 3D HCS were only collected in liquid non-solvent coagulation bath; therefore, it is important to consider the forces acting on electrospun jet when it comes in contact with the liquid in coagulation bath (Table 2). Typically, when a micro/nanoscale elastic/viscoelastic structure contacts a liquid interface, capillary forces can be strong enough to induce bending or wrinkling in such structures. ${ }^{45-47}$ Thus, when using a coagulation bath, the surface tension force $\left(F_{s}\right)$ of the non-solvent liquid will also contribute to the bending of the electrospun jet and to HCS fabrication. It was noted experimentally that the employed polymer solution was not able to penetrate through a high surface tension liquid (water) and fibers were collected randomly on the surface. Nevertheless, for low surface tension liquids, such as methanol or ethanol, the electrospun jet penetrated, coiled, and collected as 3D HCS in the coagulation bath.

Later, we kept $F_{S}$ constant by using methanol as the non-solvent liquid in the coagulation bath to study the effects of $F_{t}, F_{n}$, and $F_{v}$ on the formation of 3D HCS in the coagulation bath. Normally, $F_{v}$ will oppose the formation of HCS in both coagulation bath and on a flat collector. Table 2 shows that $F_{t}$ and $F_{n}$ acting on electrospun jet are higher when collected in a coagulation bath, than when collected on a metallic flat collector. The increase in $F_{t}$ and $F_{n}$ in coagulation bath is responsible for microscale coiling as compared to 3D nonuniform coiling in conventional electrospinning. Further, the effect of $F_{t}$ and $F_{n}$ on coil diameter was also analysed (see Figure 5). For a given needle to collector distance, an increase in the applied voltage will enhance the electric field, which will thereby increase $F_{t}$ 
and $F_{n}$ (see Eq. 3 and 4). This increase in $F_{t}$ and $F_{n}$ will increase the corresponding torque acting on the jet, which will result in more enhanced twisting of jet and thereby reduction of the coil diameter - this is in agreement with our experimental observations, see Figure 7.

Table 2. Comparison of forces experienced by electrospun jet collected onto flat collector in conventional electrospinning and coagulation bath in wet-electrospinning.

\begin{tabular}{|c|c|c|c|}
\hline Parameters & Flat collector & Coagulation bath & Comparison \\
\hline $\begin{array}{l}\text { Normal electric } \\
\text { force } \\
F_{n} \\
\left.\approx \frac{(\bar{\varepsilon}-\varepsilon)}{2} A_{n} E_{e}{ }^{2}\right)\end{array}$ & $\begin{array}{l}\bar{\varepsilon}=1 ; \varepsilon \sim 4.8 \\
\left(F_{n}\right)_{F C} \approx \frac{(-3.8)}{2} A_{n} E_{e}{ }^{2}\end{array}$ & $\begin{aligned} & \bar{\varepsilon}=32.6 ; \varepsilon \sim 4.8 ; \\
& \left(F_{n}\right)_{C B} \\
\approx & \frac{(-27.8)}{2} A_{n} E_{e}^{2}\end{aligned}$ & $\frac{\left(F_{n}\right)_{C B}}{\left(F_{n}\right)_{F C}} \approx 7.3$ \\
\hline $\begin{array}{l}\text { Tensile electric } \\
\text { force } \\
\left(F_{t} \approx \sigma A_{t} E_{e}\right)\end{array}$ & $\begin{array}{l}\sigma \approx 0 \text {, jet loses its charge } \\
\text { as it comes in contact } \\
\text { with metallic collector, } \\
\text { therefore }\left(F_{t}\right)_{F C} \approx 0\end{array}$ & $\begin{array}{c}\sigma \neq 0 \\
\left(F_{t}\right)_{C B} \neq 0\end{array}$ & $\begin{array}{l}\text { For a given time, } \\
\text { charge diffusion } \\
\text { from jet will be } \\
\text { greater on metallic } \\
\text { collector than on } \\
\text { liquid bath } \\
\qquad \frac{\left(F_{t}\right)_{C B}}{\left(F_{t}\right)_{F C}}>1\end{array}$ \\
\hline
\end{tabular}

In our experimental studies, HCS were fabricated from different concentration of PBSDLS 70:30 chloroform solutions (concentration above $20 \mathrm{wt} / \mathrm{v} \%$ ), therefore, $F_{v}$ is not considered relevant for the fabrication of HCS in a liquid bath above a certain threshold concentration. Therefore, $F_{t}, F_{n}$, and $F_{s}$ are considered primarily responsible for the formation of HCS in liquid bath. This described mechanism of formation of HCS in liquid bath is well reflected in various architectures shown in Figure 7 and can help future work aimed at obtaining HCS for a variety of applications.

a)

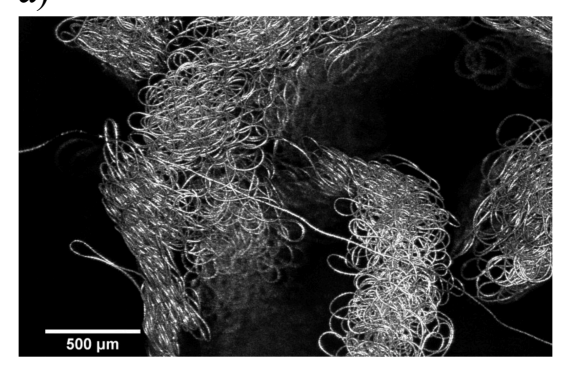

b)

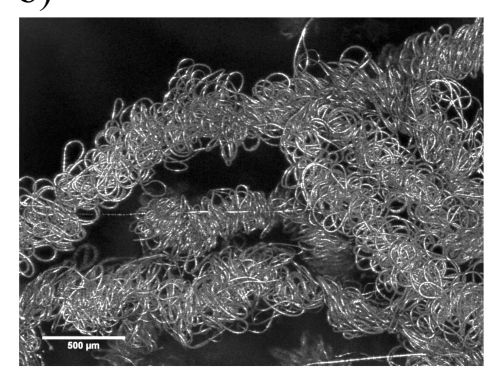

c)

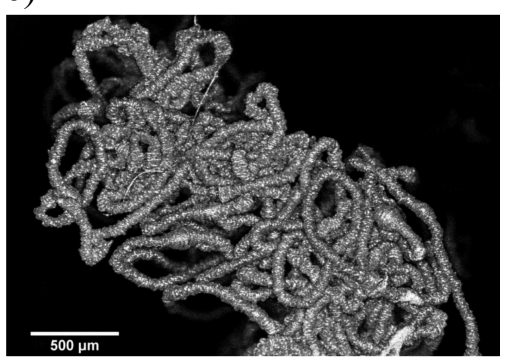

Figure 7. The effect of process parameters (forces) on HCS architecture: a) ribbon-like structures at $1 \mathrm{ml} / \mathrm{hr}$ and $9 \mathrm{kV}$; b) tangled structures at $2 \mathrm{ml} / \mathrm{hr}$ and $9 \mathrm{kV}$; c) coils at $3 \mathrm{ml} / \mathrm{hr}$ and $14 \mathrm{kV}$. The distance between the needle tip and the coagulation bath was $15 \mathrm{~cm}$.

\section{Characterization of $3 \mathrm{D} \mathrm{HCS}$}

2D membranes, as well as 3D HCS were tested for their physical, as well as mechanical properties. SEM and LSM images were used to obtain average fiber diameter for both 2D membranes and 3D HCS (Table 3), as well as to compare their morphology (Figure 8). The analysis of coiled fiber morphology in $3 \mathrm{D}$ scaffolds indicated $9.9 \pm 2.3 \mu \mathrm{m}$ average diameter, 
which is the same order of magnitude as collagen coiled fibers found in heart perimysium (diameter $\sim 2-3 \mu \mathrm{m})^{16}$. Interestingly, as can be seen from SEM in Figure 8c,d, PBS-DLS HCS are composed of fibers that also have surface porosity $(\sim 250 \mathrm{~nm})$, in contrast to fibers obtained via conventional electrospinning on a metal collector (Figure 8a,b). The native biological environment of most cells is rich with topographical features in the 10-200 nm range and cells are known to respond to both defined topographies, as well as surface roughness. ${ }^{48}$ We speculate that the surface porosity of PBS-DLS HCS may promote cell adhesion. Additionally, these pores could be further leveraged, for example, to facilitate controlled release of bioactive cues, such as growth factors, from within the polymer matrix.

a)

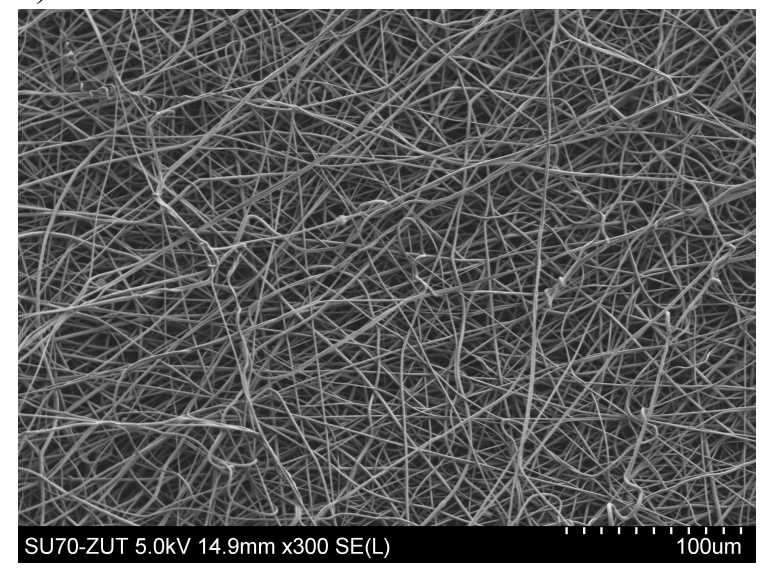

c)



b)

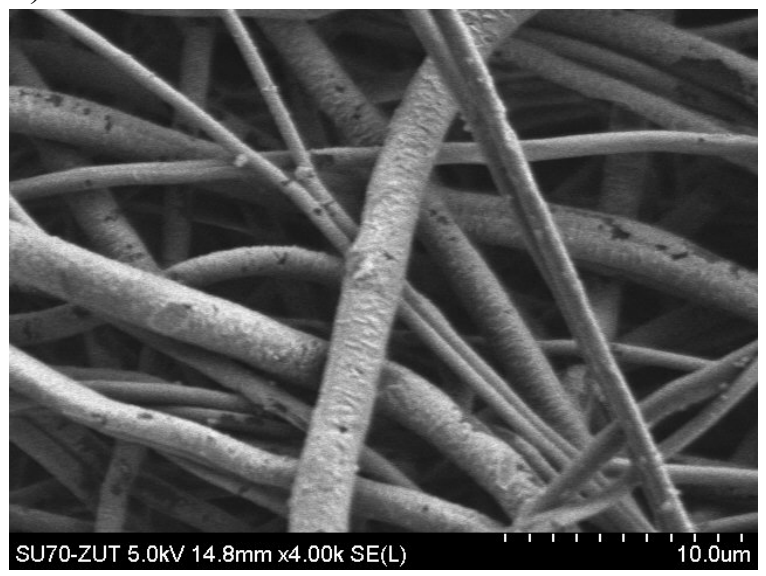

d)

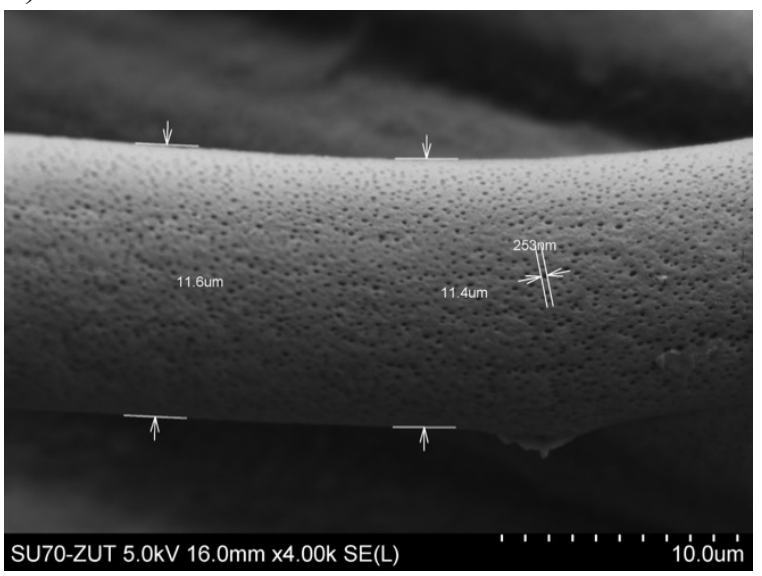

Figure 8. SEM images of electrospun mats from PBS-DLS 70:30 solution collected on (a,b) conventional flat collector covered with aluminium foil $\left(16 \mathrm{wt} / \mathrm{v} \%\right.$ in $\mathrm{CHCl}_{3}: \mathrm{MeOH} 7: 3,6$ $\mathrm{mL} / \mathrm{h}, 17 \mathrm{kV}, 16 \mathrm{~cm})$, and (c,d) on a methanol bath $\left(30 \mathrm{w} / \mathrm{v} \%\right.$ in $\mathrm{CHCl}_{3}, 7 \mathrm{~mL} / \mathrm{h}, 15 \mathrm{kV}, 23$ $\mathrm{cm})$.

The open porosity and apparent density of 2D scaffolds and 3D HCS were measured, as shown in Table 3. As expected, when compared with conventional electrospun 2D non-woven mats, 3D HCS obtained by wet electrospinning had higher open porosity. This threedimensional interconnected porosity of these 3D architectures (Figure 9) should facilitate better cell distribution within the material and, thus, assembly of functional tissues. 
Collectively, the 3D HCS structure with high open porosity and surface nanoporosity should be well suited for cell seeding and ultimately heart tissue regeneration.

Table 3. Open porosity of traditional and wet electrospun scaffolds.

\begin{tabular}{|c|c|c|c|c|c|c|c|}
\hline Sample & Conditions & $\begin{array}{l}\mathrm{V} \\
(\mathrm{kV})\end{array}$ & $\begin{array}{l}\text { Flow } \\
\text { rate } \\
\left(\mathrm{mLh}^{-1}\right)\end{array}$ & $\begin{array}{l}\mathrm{E} \\
(\mathrm{kV} / \mathrm{cm})\end{array}$ & $\begin{array}{l}\mathrm{d}_{\mathrm{av}} \\
(\mu \mathrm{m})\end{array}$ & $\begin{array}{l}\mathrm{C}_{\mathrm{av}} \\
(\mu \mathrm{m})\end{array}$ & $\begin{array}{l}\text { Open } \\
\text { porosity } \\
(\%)\end{array}$ \\
\hline $\begin{array}{l}\text { PBS-DLS } \\
70: 30,20 \\
\mathrm{wt} / \mathrm{v} \% \text { in } \\
\mathrm{CHCl}_{3}\end{array}$ & $\begin{array}{l}\text { Methanol } \\
\text { coagulation } \\
\text { bath }\end{array}$ & 15 & 10 & 0.65 & $\begin{array}{l}9.9 \pm 2.4 \\
{[12.5 \pm 4]}\end{array}$ & $370.83 \pm 50.17$ & $\begin{array}{l}85.4 \\
{[84]}\end{array}$ \\
\hline $\begin{array}{l}\text { PBS-DLS } \\
70: 30,16 \\
\mathrm{wt} / \mathrm{v} \% \text { in } \\
\mathrm{CHCl}_{3}: \\
\mathrm{MeOH}_{(7: 3)}\end{array}$ & $\begin{array}{l}\text { Conventional } \\
\text { electrospinning }\end{array}$ & 17 & 6 & 1.0 & $0.86 \pm 0.30$ & - & 76.1 \\
\hline
\end{tabular}

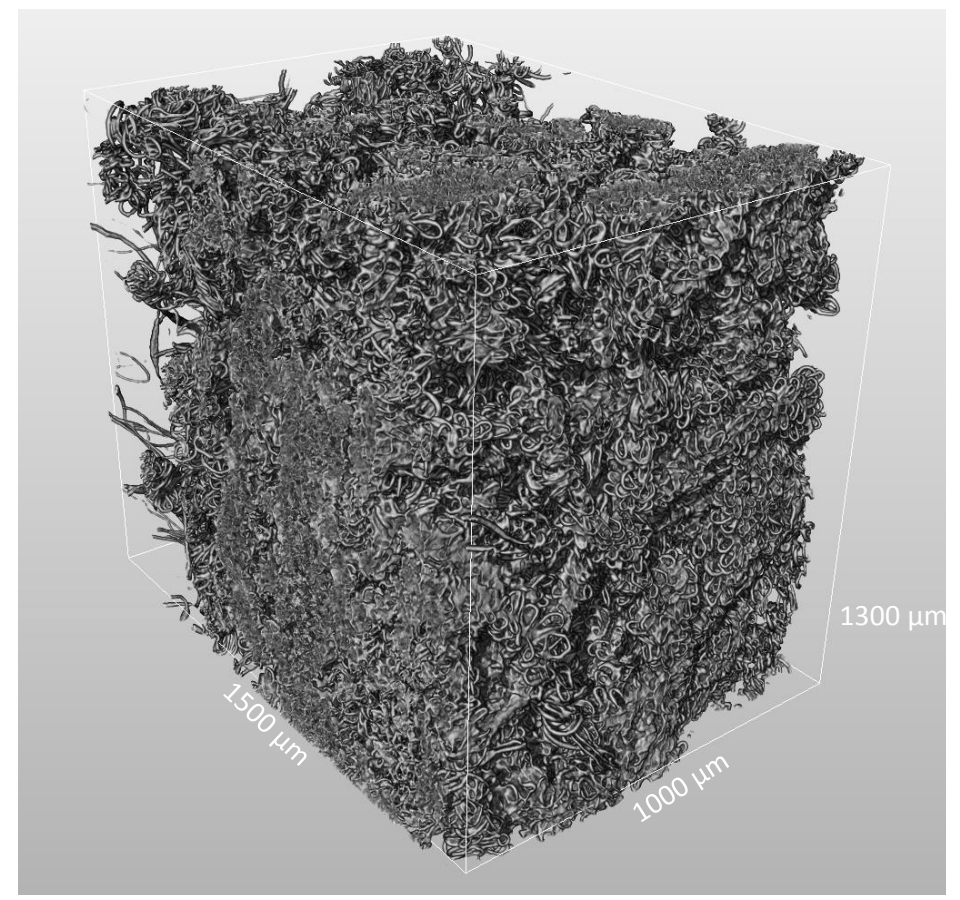

Figure 9. $\mu \mathrm{CT}$ scan of HCS revealing interconnected porosity throughout the entire 3D scaffold.

Finally, we conducted mechanical tests to compare the tensile properties of conventionally electrospun 2D scaffolds with 3D HCS (Figure 10). For the 2D scaffolds, Young's modulus $(E)$ was $11 \pm 0.45 \mathrm{MPa}$ and tensile strength $(\sigma)$ was $3.04 \pm 0.21 \mathrm{MPa}$. For the $3 \mathrm{D} \mathrm{HCS}$, the values are markedly lower: $E=1.83 \pm 0.8 \mathrm{MPa}$ and $\sigma=0.3 \pm 0.18 \mathrm{MPa}$. The lower values of $E$ and $\sigma$ of 3D HCS are attributed to its highly coiled and porous nature. Further, the mechanical properties of fabricated 3D membranes are a better match for the properties of cardiac tissue: $E=0.2-0.5 \mathrm{MPa}$ and $\sigma=3-15 \mathrm{kPa} .{ }^{49}$ Therefore, we conclude that our 
membranes with the combination of elastomeric PBS-DLS and HCS morphology should be well suited to facilitate engineered cardiac tissue contractility.
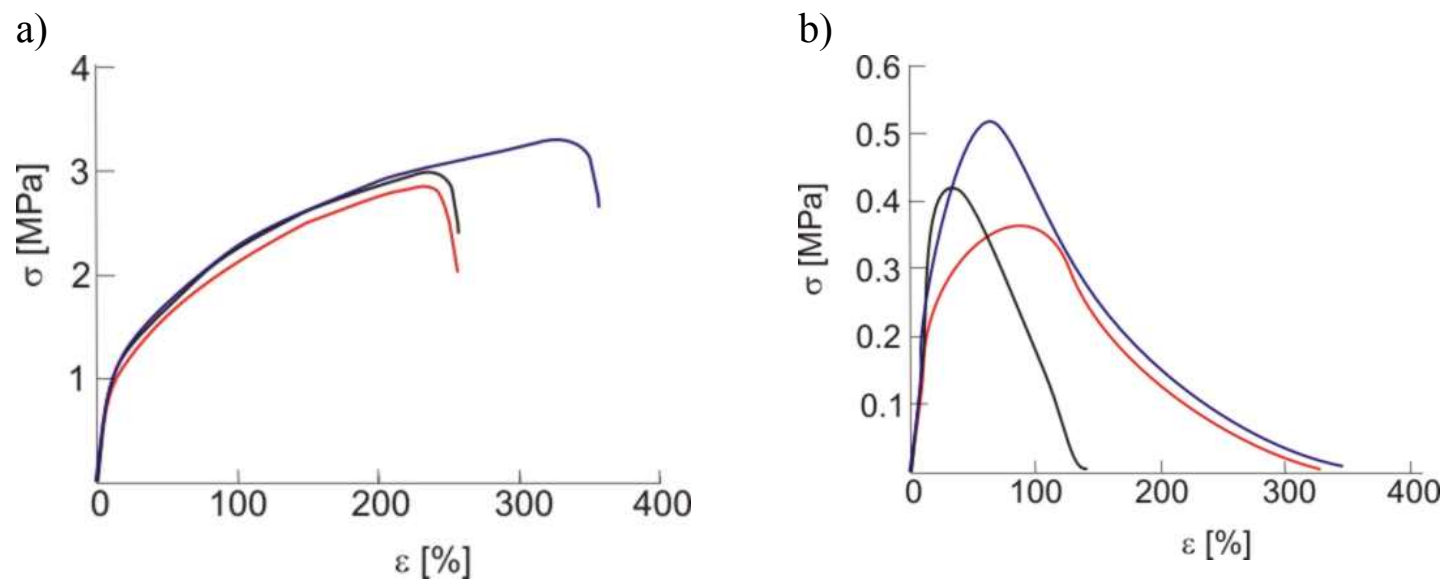

Figure 10. Stress-strain curves of three representative 2D electrospun PBS-DLS scaffolds (a), and three representative 3D HCS (b).

\section{Cytocompatiblity tests of $3 \mathrm{D}$ HCS}

Cytocompatiblity tests were performed in order to confirm the potential of obtained HCS for functional tissue engineering. First, cytotoxicity assessment using extracts from conventionally electrospun $2 \mathrm{D}$ scaffolds ( 24 hours in complete media at $37^{\circ} \mathrm{C}$ ) indicated no cytotoxicity of electrospun PBS-DLS: cell viability of L929 murine fibroblasts after 24 hours exposure to undiluted extracts was $101 \pm 1 \%$ of vehicle control ( $\mathrm{n}=3$ samples, each extract was tested in triplicate). Likewise, following 48 hours of direct contact with samples, no growth inhibition zone was observed and resazurin viability test indicated $82 \pm 7 \%$ viability $(\mathrm{n}=5$ discs) of L929 cells in wells without discs, which is above the $70 \%$ threshold indicating potential cytotoxicity. The reduction in viability is likely due to mechanical trauma following removal of discs prior to the viability assay, as the discs were noted to stick slightly within the wells.

Further, cytocompatibility of conventionally electrospun 2D PBS-DLS scaffolds and 3D HCS was also evaluated by seeding L929 murine fibroblasts directly on samples of the materials (Figure 11). After 18 hours, the cell culture inserts holding the materials were transferred to fresh wells and cell viability was assessed using the resazurin assay - this value was considered to represent the adhesion of cells to the test materials. Next, cells were fed with fresh complete media and cell viability (Figure 11a) was assessed after incubation for 48 hours, after which cells were again fed and viability was assessed after a further 96 hours (144 hours after transfer to fresh wells, 162 hours total) of culture - these values represent proliferation of cells on the materials. The initial adhesion on HCS (Figure 11a) was observed to be lower, likely due to the loose, open morphology of the materials permitting cells to fall through, while the more compact nature of the flat 2D mats acts as a filter. In fact, for HCS samples, after transferring all cell culture inserts to fresh wells, we observed marked viability signal from the well bottom. Importantly, after maintaining the scaffolds in culture, we observe higher viability of L929 cells on HCS, as compared to flat 2D mats (Figure 11a) and the growth ratio (Figure 11b), calculated per sample as the ratio of viability after each incubation time to the initial value (after 18 hours), was significantly higher for HCS after both 48 hours $(2.6 v s .1 .6, \mathrm{p}=0.02)$ and 144 hours $(10.0 v s .5 .3, \mathrm{p}=0.01)$. 



Figure 11. a) L929 cell viability (mean \pm SE) on conventionally electrospun $2 \mathrm{D}$ scaffolds $(n=5)$ and HCS $(n=10) 18$ hours after seeding and following additional 48 hours and 144 hours of culture. $\mathrm{b}$ ) Ratios (mean $\pm \mathrm{SD}$ ) of viability after additional incubation time versus initial value after 18 hours, representing proliferation of L929 cells on test materials.

This is also visualized by $\mu \mathrm{CT}$ scans of samples labelled with iodine to visualize cells present on the samples (Figure 12). We observe more cells within the HCS sample (b) as compared to the conventionally electrospun mats (a). Further, SEM micrographs clearly show cell spreading on HCS (Figure 13), with cells bridging spring coils and adhering strongly to the surface, perhaps due to previously discussed nanoporosity (not revealed in these micrographs as samples were dried in supercritical $\mathrm{CO}_{2}$ resulting in pore collapse).

a)

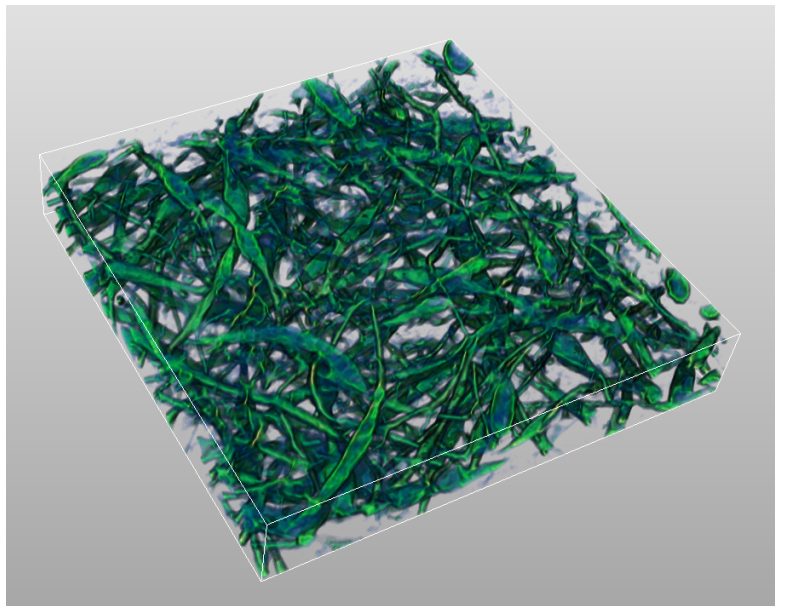

b)

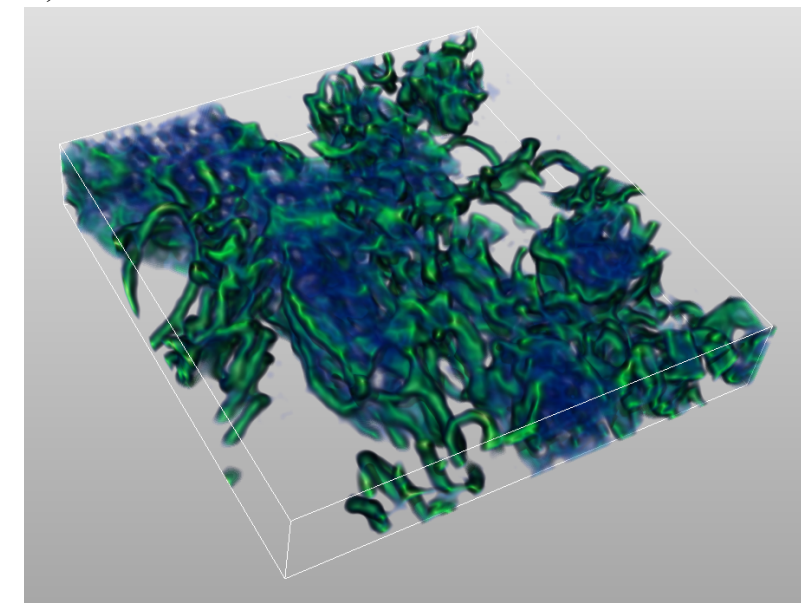

Figure 12. $\mu \mathrm{CT}$ cross-section $(300 \times 300 \times 50 \mu \mathrm{m})$ of conventionally electrospun $2 \mathrm{D}$ scaffold (a) and HCS (b) after seeding with L929 cells and 144 hours of culture. Violet to blue color indicates presence of cells labelled with iodine. 
a)

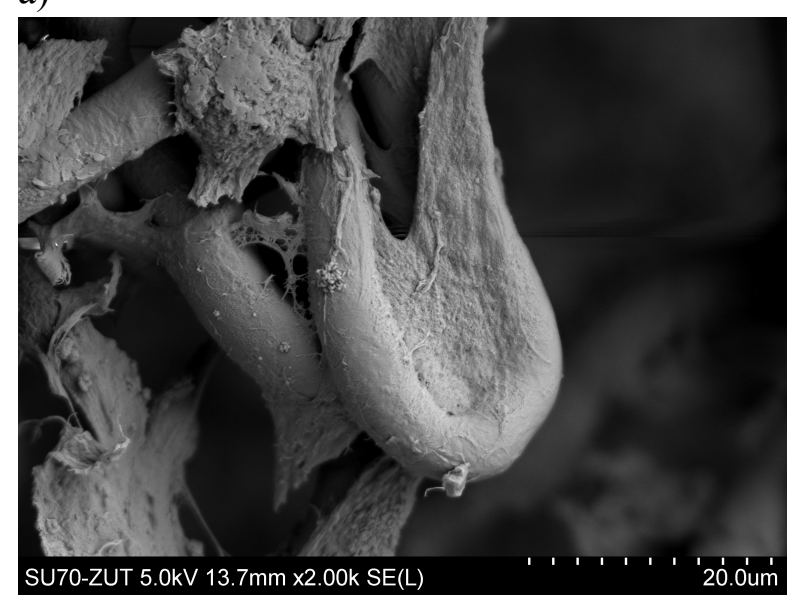

b)

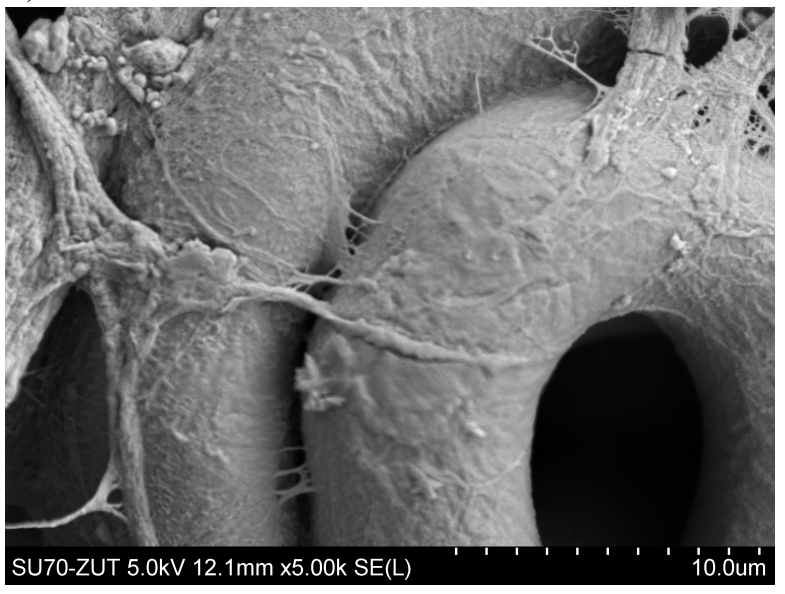

Figure 13. SEM micrographs showing L929 cells after 144 hours of culture on HCS at different magnifications.

Collectively, we conclude that electrospun PBS-DLS materials are cytocompatible, based upon lack of cytotoxicity in extract and direct contact tests, as well as observed adhesion and growth of cells. Meanwhile, the marked increase in proliferation on HCS samples confirms the suitability of these $3 \mathrm{D}$ materials as scaffolds for soft tissue engineering.

\section{CONCLUSIONS}

In conclusion, microscale helically coiled structures were fabricated by wetelectrospinning from elastomeric poly(butylene succinate-co-dilinoleic succinate) copolymer with a 70:30 wt.\% ratio of hard to soft segments. Importantly, for the first time, we demonstrate that by tuning process parameters, a range of HCS architectures could be obtained, from flatter, ribbon-like coils to spring-like coils that mimic morphology of coiled fibers found in heart perimysium. Further, the fabricated 3D HCS have higher open porosity than conventionally electrospun 2D mats and the mechanical properties of PBS-DLS HCS also more closely resemble those of cardiac tissue. In terms of cytocompatibility, extract and direct contact cell culture tests did not indicate cytotoxicity of electrospun PBS-DLS, while seeding cells on HCS resulted in $\sim 2$-fold higher proliferation than on conventionally electrospun 2D scaffolds. We conclude that the PBS-DLS HCS are well suited for applications in functional heart tissue engineering, as their morphology will help in cyclic contraction/retraction motion of the engineered cardiac tissue. Finally, our mechanics analysis indicates that HCS obtained via wet electrospinning are formed due to the combination of tensile and normal component of electric force acting on the electrospun jet, as well as the surface tension of the non-solvent bath. The discussed mechanism behind the formation of helically coiled structures in non-solvent bath may aid in the design and fabrication of HCS for functional tissue engineering, as well as various other applications. 


\section{ACKNOWLEDGEMENTS}

This work is financially supported by National Science Centre, Poland, under the HARMONIA scheme (agreement No. UMO-2014/14/M/ST8/00610). The authors thank Dr. Karol Fijałkowski (Faculty of Biotechnology and Animal Husbandry, ZUT) for access to the multifunctional plate reader. HDW is the recipient of the Livio Norzi Professorial Chair in Materials Science at the Weizmann Institute.

\section{REFERENCES}

(1) Sanchez, C.; Arribart, H.; Giraud Guille, M. M. Biomimetism and bioinspiration as tools for the design of innovative materials and systems. Nat. Mater. 2005, 4 (4), $277-$ 288 DOI: $10.1038 /$ nmat1339.

(2) Jang, K. I.; Li, K.; Chung, H. U.; Xu, S.; Jung, H. N.; Yang, Y.; Kwak, J. W.; Jung, H. H.; Song, J.; Yang, C.; et al. Self-assembled three dimensional network designs for soft electronics. Nat. Commun. 2017, 8, 15894 DOI: 10.1038/ncomms15894.

(3) Saini, D.; Behlow, H.; Podila, R.; Dickel, D.; Pillai, B.; Skove, M. J.; Serkiz, S. M.; Rao, A. M. Mechanical resonances of helically coiled carbon nanowires. Sci. Rep. 2014, 4, 5542 DOI: $10.1038 /$ srep05542.

(4) Hoshizawa, H.; Suzuki, M.; Shirai, H.; Hanabusa, K.; Yang, Y. Fabrication of Helical Mesoporous Silica Nanostructures Using Gelators and the Mixtures with CTAC. Sen-I Gakkaishi 2009, 65 (2), 78-85 DOI: 10.2115/fiber.65.80.

(5) Giraldo, O.; Marquez, M.; Brock, S. L.; Suib, S. L.; Hillhouse, H.; Tsapatsis, M. Spontaneous formation of inorganic helical fibers and rings. J. Am. Chem. Soc. 2000, 122 (49), 12158-12163 DOI: 10.1021/ja0018872.

(6) Lin, Y.; Qiao, Y.; Gao, C.; Tang, P.; Liu, Y.; Li, Z.; Yan, Y.; Huang, J. Tunable onedimensional helical nanostructures: From supramolecular self-assemblies to silica nanomaterials. Chem. Mater. 2010, 22 (24), 6711-6717 DOI: 10.1021/cm102181e.

(7) Kong, X. Y.; Wang, Z. L. Spontaneous Polarization-Induced Nanohelixes, Nanosprings, and Nanorings of Piezoelectric Nanobelts. Nano Lett. 2003, 3 (12), 1625-1631 DOI: $10.1021 / \mathrm{n} 1034463 \mathrm{p}$.

(8) Zander, N. Hierarchically Structured Electrospun Fibers. Polymers (Basel). 2013, 5 (1), 19-44 DOI: 10.3390/polym5010019.

(9) Lin, T.; Wang, H.; Wang, X. Self-crimping bicomponent nanofibers electrospun from polyacrylonitrile and elastomeric polyurethane. Adv. Mater. 2005, 17 (22), 2699-2703 DOI: 10.1002/adma.200500901.

(10) Kessick, R.; Tepper, G. Microscale polymeric helical structures produced by electrospinning. Appl. Phys. Lett. 2004, 84 (23), 4807-4809 DOI: 10.1063/1.1762704.

(11) Xin, Y.; Huang, Z. H.; Yan, E. Y.; Zhang, W.; Zhao, Q. Controlling poly(p-phenylene vinylene)/poly(vinyl pyrrolidone) composite nanofibers in different morphologies by electrospinning. Appl. Phys. Lett. 2006, 89 (5), 053101 DOI: 10.1063/1.2236382.

(12) Shin, M. K.; Kim, S. I.; Kim, S. J. Controlled assembly of polymer nanofibers: From helical springs to fully extended. Appl. Phys. Lett. 2006, 88 (22), 223109 DOI: 10.1063/1.2208689. 
(13) Fleischer, S.; Feiner, R.; Shapira, A.; Ji, J.; Sui, X.; Daniel Wagner, H.; Dvir, T. Spring-like fibers for cardiac tissue engineering. Biomaterials 2013, 34 (34), 85998606 DOI: 10.1016/j.biomaterials.2013.07.054.

(14) Butler, D. L.; Goldstein, S. A.; Guilak, F. Functional Tissue Engineering: The Role of Biomechanics. J. Biomech. Eng. 2000, 122 (6), 570 DOI: 10.1115/1.1318906.

(15) Guilak, F.; Butler, D. L.; Goldstein, S. A.; Baaijens, F. P. T. Biomechanics and mechanobiology in functional tissue engineering. J. Biomech. 2014 DOI: 10.1016/j.jbiomech.2014.04.019.

(16) Robinson, T. F.; Geraci, M. a.; Sonnenblick, E. H.; Factor, S. M. Coiled perimysial fibers of papillary muscle in rat heart: morphology, distribution, and changes in configuration. Circ. Res. 1988, 63 (3), 577-592 DOI: 10.1161/01.RES.63.3.577.

(17) Freed, L. E.; Engelmayr, G. C.; Borenstein, J. T.; Moutos, F. T.; Guilak, F. Advanced material strategies for tissue engineering scaffolds. Adv. Mater. 2009, 21 (32-33), 3410-3418 DOI: 10.1002/adma.200900303.

(18) Jung, Y.; Park, M. S.; Lee, J. W.; Kim, Y. H.; Kim, S. H.; Kim, S. H. Cartilage regeneration with highly-elastic three-dimensional scaffolds prepared from biodegradable poly(l-lactide-co-e-caprolactone). Biomaterials 2008, 29 (35), 46304636 DOI: 10.1016/j.biomaterials.2008.08.031.

(19) Ki, C. S.; Kim, J. W.; Hyun, J. H.; Lee, K. H.; Hattori, M.; Rah, D. K.; Park, Y. H. Electrospun three-dimensional silk fibroin nanofibrous scaffold. J. Appl. Polym. Sci. 2007, 106 (6), 3922-3928 DOI: 10.1002/app.26914.

(20) Yokoyama, Y.; Hattori, S.; Yoshikawa, C.; Yasuda, Y.; Koyama, H.; Takato, T.; Kobayashi, H. Novel wet electrospinning system for fabrication of spongiform nanofiber 3-dimensional fabric. Mater. Lett. 2009, 63 (9-10), 754-756 DOI: 10.1016/J.MATLET.2008.12.042.

(21) Díez-Pascual, A. M.; Díez-Vicente, A. L. Electrospun fibers of chitosan-grafted polycaprolactone/poly(3-hydroxybutyrate-co-3-hydroxyhexanoate) blends. J. Mater. Chem. B 2016, 4 (4), 600-612 DOI: 10.1039/C5TB01861G.

(22) Atila, D.; Keskin, D.; Tezcaner, A. Cellulose acetate based 3-dimensional electrospun scaffolds for skin tissue engineering applications. Carbohydr. Polym. 2015, 133, 251261 DOI: 10.1016/J.CARBPOL.2015.06.109.

(23) Atila, D.; Keskin, D.; Tezcaner, A. Crosslinked pullulan/cellulose acetate fibrous scaffolds for bone tissue engineering. Mater. Sci. Eng. C 2016, 69, 1103-1115 DOI: 10.1016/J.MSEC.2016.08.015.

(24) Colpankan Gunes, O.; Unalan, I.; Cecen, B.; Ziylan Albayrak, A.; Havitcioglu, H.; Ustun, O.; Ergur, B. U. Three-dimensional silk impregnated HAp/PHBV nanofibrous scaffolds for bone regeneration. Int. J. Polym. Mater. Polym. Biomater. 2018, 1-12 DOI: 10.1080/00914037.2018.1443928.

(25) Shin, T. J.; Park, S. Y.; Kim, H. J.; Lee, H. J.; Youk, J. H. Development of 3-D poly(trimethylenecarbonate-co-e-caprolactone)-block-poly(p-dioxanone) scaffold for bone regeneration with high porosity using a wet electrospinning method. Biotechnol. Lett. 2010, 32 (6), 877-882 DOI: 10.1007/s10529-010-0235-7.

(26) Hong, S.; Kim, G. Fabrication of size-controlled three-dimensional structures consisting of electrohydrodynamically produced polycaprolactone micro/nanofibers. Appl. Phys. A 2011, 103 (4), 1009-1014 DOI: 10.1007/s00339-011-6381-5.

(27) Coburn, J. M.; Gibson, M.; Monagle, S.; Patterson, Z.; Elisseeff, J. H. Bioinspired 
nanofibers support chondrogenesis for articular cartilage repair. Proc. Natl. Acad. Sci. 2012, 109 (25), 10012-10017 DOI: 10.1073/pnas.1121605109.

(28) Kasuga, T.; Obata, A.; Maeda, H.; Ota, Y.; Yao, X.; Oribe, K. Siloxane-poly(lactic acid)-vaterite composites with 3D cotton-like structure. J. Mater. Sci. Mater. Med. 2012, 23 (10), 2349-2357 DOI: 10.1007/s10856-012-4607-5.

(29) Gang, E. H.; Ki, C. S.; Kim, J. W.; Lee, J.; Cha, B. G.; Lee, K. H.; Park, Y. H. Highly porous three-dimensional poly(lactide-co-glycolide) (PLGA) microfibrous scaffold prepared by electrospinning method: A comparison study with other PLGA type scaffolds on its biological evaluation. Fibers Polym. 2012, 13 (6), 685-691 DOI: 10.1007/s12221-012-0685-8.

(30) Kim, M. S.; Son, J.; Lee, H.; Hwang, H.; Choi, C. H.; Kim, G. Highly porous 3D nanofibrous scaffolds processed with an electrospinning/laser process. Curr. Appl. Phys. 2014, 14 (1), 1-7 DOI: 10.1016/J.CAP.2013.10.008.

(31) Kim, M. S.; Kim, G. Electrohydrodynamic Jet Process for Pore-Structure-Controlled 3D Fibrous Architecture As a Tissue Regenerative Material: Fabrication and Cellular Activities. Langmuir 2014, 30 (28), 8551-8557 DOI: 10.1021/la501080c.

(32) Kostakova, E.; Seps, M.; Pokorny, P.; Lukas, D. Study of polycaprolactone wet electrospinning process. Express Polym. Lett. 2014, 8 (8), 554-564 DOI: 10.3144/expresspolymlett.2014.59.

(33) Taskin, M. B.; Xu, R.; Gregersen, H.; Nygaard, J. V.; Besenbacher, F.; Chen, M. Three-Dimensional Polydopamine Functionalized Coiled Microfibrous Scaffolds Enhance Human Mesenchymal Stem Cells Colonization and Mild Myofibroblastic Differentiation. ACS Appl. Mater. Interfaces 2016, 8 (25), 15864-15873 DOI: 10.1021/acsami.6b02994.

(34) Sonseca, A.; El Fray, M. Enzymatic synthesis of an electrospinnable poly(butylene succinate-co-dilinoleic succinate) thermoplastic elastomer. RSC Adv. 2017, 7 (34), 21258-21267 DOI: 10.1039/C7RA02509B.

(35) Liverani, L.; Piegat, A.; Niemczyk, A.; El Fray, M.; Boccaccini, A. R. Electrospun fibers of poly(butylene succinate-co-dilinoleic succinate) and its blend with poly(glycerol sebacate) for soft tissue engineering applications. Eur. Polym. J. 2016, 81, 295-306 DOI: 10.1016/j.eurpolymj.2016.06.009.

(36) Jäger, A.; Gromadzki, D.; Jäger, E.; Giacomelli, F. C.; Kozlowska, A.; Kobera, L.; Brus, J.; Ríhová, B.; El Fray, M.; Ulbrich, K.; et al. Novel “soft” biodegradable nanoparticles prepared from aliphatic based monomers as a potential drug delivery system. Soft Matter. 2012, p 4343.

(37) Kozłowska, A.; Gromadzki, D.; El Fray, M.; Štêpánek, P. Morphology evaluation of biodegradable copolyesters based on dimerized fatty acid studied by DSC, SAXS and WAXS. Fibres Text East Eur 2008, 16, 85.

(38) Wcisłek, A.; Sonseca Olalla, A.; McClain, A.; Piegat, A.; Sobolewski, P.; Puskas, J.; El Fray, M. Enzymatic Degradation of Poly(butylene succinate) Copolyesters Synthesized with the Use of Candida antarctica Lipase B. Polymers (Basel). 2018, 10 (6), 688 DOI: $10.3390 /$ polym10060688.

(39) ISO. Biological evaluation of medical devices-Part 5: tests for in vitro cytotoxicity; Geneva, Switzerland, 2009.

(40) Riss, T. L.; Moravec, R. A.; Niles, A. L.; Duellman, S.; Benink, H. A.; Worzella, T. J.; Minor, L. Cell Viability Assays. In Assay Guidance Manual; Sittampalam, G., 
Coussens, N., Eds.; Eli Lilly \& Company and the National Center for Advancing Translational Sciences: Bethesda, MD, 2004.

(41) Spinks, G. M. Stretchable artificial muscles from coiled polymer fibers. J. Mater. Res. 2016, 31 (19), 2917-2927 DOI: 10.1557/jmr.2016.316.

(42) Ross, A. L. Cable Kinking Analysis and Prevention. J. Eng. Ind. 1977, 99 (February), 112 DOI: $10.1115 / 1.3439123$.

(43) Feng, J. J. The stretching of an electrified non-Newtonian jet: A model for electrospinning. Phys. Fluids 2002, 14 (11), 3912-3926 DOI: 10.1063/1.1510664.

(44) Reneker, D. H.; Yarin, A. L. Electrospinning jets and polymer nanofibers. Polymer (Guildf). 2008, 49 (10), 2387-2425 DOI: 10.1016/j.polymer.2008.02.002.

(45) Neukirch, S.; Roman, B.; de Gaudemaris, B.; Bico, J. Piercing a liquid surface with an elastic rod: Buckling under capillary forces. J. Mech. Phys. Solids 2007, 55 (6), 12121235 DOI: 10.1016/j.jmps.2006.11.009.

(46) Roman, B.; Bico, J. Elasto-capillarity: Deforming an elastic structure with a liquid droplet. J. Phys. Condens. Matter 2010, 22 (49), 493101 DOI: 10.1088/09538984/22/49/493101.

(47) Huang, J.; Juszkiewicz, M.; De Jeu, W. H.; Cerda, E.; Emrick, T.; Menon, N.; Russell, T. P. Capillary wrinkling of floating thin polymer films. Science (80-. ). 2007, 317 (5838), 650-653 DOI: 10.1126/science.1144616.

(48) Lim, J. Y.; Donahue, H. J. Cell Sensing and Response to Micro- and Nanostructured Surfaces Produced by Chemical and Topographic Patterning. Tissue Eng. 2007, 13 (8), 1879-1891 DOI: 10.1089/ten.2006.0154.

(49) Chen, Q.-Z.; Bismarck, A.; Hansen, U.; Junaid, S.; Tran, M. Q.; Harding, S. E.; Ali, N. N.; Boccaccini, A. R. Characterisation of a soft elastomer poly(glycerol sebacate) designed to match the mechanical properties of myocardial tissue. Biomaterials 2008, 29 (1), 47-57 DOI: 10.1016/j.biomaterials.2007.09.010. 